\title{
Identity Crisis of the Linguistic Minorities in The Process of Acculturation with Reference to Secondary Curriculum in the State of West Bengal, India
}

\author{
Russell Al Farabi \\ Assistant Professor, Department of Education \\ Ramakrishna Mission Sikshanamandira (Autonomous College) \\ Affiliated to The University of Calcutta, Kolkata, India
}

\begin{abstract}
The problems of language planning in multilingual countries cannot be viewed from the monolingual perspective which is available from the developed countries. Every multicultural, multilingual country must find its own unique solution keeping in view the sociolinguistic and psychological contexts of its language use. Language is one of the most debated topics in Indian education. Being a democratic, multilingual country, India and its educators are constantly grappling with the issue of what languages should be the media of instruction, particularly with reference to speakers of minority languages, some of which lack standardized written forms. India has vast majority of speakers of over 1,600 mother tongues dominated by only 15 scheduled languages. Unfortunately, the social policy planners have failed to take adequate notice of the fact that the social and psychological consequences of neglect of its multicultural and multilingual reality. The language problems in India must be viewed within a holistic framework and that, apart from the emotional and intuitive arguments often advanced in favour of mother tongue maintenance, there is a need for promotion of mother tongues through their educational sue and through other means.

The present study contains the background and conceptual knowledge about acculturation and the problem of ethnic minorities and the reason behind selecting such area as study for research. This study would help to understand the issues associated with the disproportional representation of culturally and linguistically diverse learners in Education in West Bengal, India. Here the researcher also focused on the present curriculum of secondary level in the state of West Bengal, India and tried to locate the identity crisis of the linguistic minorities through several qualitative work related to the topic.
\end{abstract}

Keywords: Linguistic Minority, Minority Languages, Multiculturalism, Multilingual Education 


\section{Introduction}

Education involves acquiring conceptual schemes. It is not merely collecting disjointed knowledge. To learn is to connect, and students must make meaning of new knowledge in relation to their experiences and what they know. Educators then must understand student experiences and build onthem. And because their experiences are different, their identities are produced differently. This understanding is essential if teachers are to provide students with the analytical tools to challenge negative experiences and deal with problems of unresolved identities.

Language is one of the most debated topics in Indian education. Being a democratic, multilingual country, India and its educators are constantly grappling with the issue of what languages should be the media of instruction, particularly with reference to speakers of minority languages, some of which lack standardized written forms.

India's linguistic diversity can be attributed to:

(i) Different waves of invasion and colonialization (the Aryans, the Mughal, the Portuguese, the British)

(ii) Free migrations within and between the different states and union territories;

(iii) Political influences leading to the linguistic reorganization of states following Indian Independence in 1947; and

(iv)Presence of different ethnic and religious minorities distributed throughout India (Buddhists Jains, Sikhs, Muslims, Christians, Zoroastrians, and others).

In a democracy such as India, where people are divided in terms of religion, language, caste, race, culture, and socio-economic factors, one of the tasks of the framers of the Constitution of India was to devise safeguards for the country's different minorities. At the time (1950), the demographic scene presented a peculiar composition. There were politically recogni7ed minorities, often with religious identities, such as the Sikhs, Muslims, Christians, Parsees and Anglo-Indians (born of mixed marriages between the English and Indians). In addition, a very large number of other cultural and linguistic groups, could be distinguished within the population and often demanded to be recognized as scheduled castes and tribes.

In the case of India, in addition to religious and ethnic minorities, one can also identify different types of linguistic minorities:

(i) Speakers of minor languages (languages not included in schedule VIII of the Constitution);

(ii) Speakers of major languages who become minorities as a result of migration (e.g., Telugu migrants in the Kannada-speaking state of Karnataka); 
(iii) Speakers belonging to scheduled castes and tribes (e.g., Gondi, Santhali, etc.);

(iv) Religious minorities, e.g., Urdu speaking Muslims all over India

(v) Linguistic minorities who speak major languages but are a minority because they lack numerical strength in their jurisdiction of residence (e.g., speakers of Sindhi, Kashmiri, etc.); and, finally,

(vi) Ethnic minorities (e.g., Anglo-Indians, many of whom claim English as their native language).

\subsection{Language and Identity}

When education goes under the banner of human resource development but at the same time ignores the most complete and complex form of resource with which a child joins school - human language - the inherent contradiction is too compelling to pass off because, for millions of children who are forced to seek formal education in schools where curriculum and language of instruction has no relationship with their home language, this neglect of mother tongue spells their destiny. In the name of unity, standardization, integration, modernization and homogenization, so many people are stripped of their cultural rootedness and their primordial pride through loss of one of their most primary identity tags - mother tongue - and, in the process, kept out of the privileges of a majority dominated elitist society, that equality of opportunity remains a vague slogan.

\subsection{Rationale of the Study}

Pedagogy should be developed around identity and meaning for all students. Pedagogy, the process of knowledge production and reproduction, is concerned with the content and methods of teaching. It involves the teaching process that encompasses interactive discourse as well as practice. Both educational discourse (what is said and written) an deducational practice (what is done in terms of activities) are guided by ideologies of the dominant group. Pedagogy, therefore, mediates the organization of social reality and change through the language and signs of the majority culture. What effect does this have on minority group children? This question is particularly significant in multilingual countries that have a large diversity of minority ethno-cultural groups. Then, Educators then have a responsibility to consult local culture while being conscious of individual context and humanity in an effort to avoid oppression of the linguistic minorities.

So an analysis of identity issues in the process of acculturation in the lives of linguistic minorities is extremely needed. Therefore, need to evaluate the cultural shock of the linguistic minorities in the process of acculturation through educational curriculum in West Bengal, India has been urgently felt. 


\subsection{Research Questions}

Do the culturally and linguistically diverse groups get any psychological shelter of mind in the existing curriculum?

$>$ How far the suggestion of NCF 2005 is reflected in the existing curriculum to protect the basic needs of the linguistic minorities?

Do the Linguistic Minorities feel any problem of acculturation?

$>$ How do the teachers confront with the assessment of students who are culturally and linguistically diverse?

$>$ Do the linguistic minorities feel identical with the existing curriculum of West Bengal?

\subsection{Objectives of the Study}

* The study would locate the identity crisis of the linguistic minorities.

* The study would seek to understand the attitudinal mindset of the linguistic minority in the problem of acculturation.

* It would find out the issues associated with the disproportional representation of culturally and linguistically diverse learners in Education in West Bengal.

* The study would focus on the challenges confronting educators when assessing students from culturally and linguistically diverse groups in West Bengal, India.

* It would locate the limitation caused by the composite culture specific Pedagogy as recommended by NCF 2005 and NCFTE 2009.

\subsection{Delimitations}

The present study has been delimited in the state of West Bengal in India. Researcher would analyse the content in order to find out the linguistic balance. The researcher would analyse the texts of both Bengali( $1^{\text {st }}$ language $)$ and English( $\left(2^{\text {nd }}\right.$ language $)$ in the existing curriculum of West Bengal Board of Secondary Education. 


\section{LICNAEDUCATION \\ 27-29 March, 2020 \\ Oxford, United Kingdom}

\section{Methods, Analysis \& Discussion}

\subsection{Methods}

The present research being a qualitative type of study in the domain of education, the researcher was aware of the fact that the analysis of data, gathered by a wide variety of methods and techniques had to be on a holistic perspective and studying real world situations as they unfolded naturally, non-manipulatively and inconspicuously with openness to whatever emerges without predetermined constrains on outcomes. For reviewing, analyzing and interpreting data methodically the present researcher has gone through the process of Content Analysis and Concept Analysis.

\subsection{Review of Related Literature}

Jacob (1972) found that the problems of the linguistic minorities lied in the implementation of constitutional safeguards for linguistic minorities. Hasnain (2007) opined for incorporating all tribal languages into mainstream education in order to remove the alienation of Urdu speakers or other linguistic groups. Simpson (2007) investigated the relation of the regional languages tothe national, ethnic, and cultural identity, and examined the status of and interactions between themajority, official, and minority languages.Benedikter(2009) opined that linguistic minorities in India often feel discriminated because of the concurrent language policy of the Union and the States. Vanishree(2011) examined the provision for linguistic diversity and linguistic minorities in India by presenting an overview of the existing linguistic diversity in India and the historical background that had contributed to the present diversity. Gorter (2012) argued that the Minority Languages in the Linguistic Landscape provided an innovative approach to the written displays of minority languages in public space.Bakshi(2013) explored the status and role of Mewati, a dialect generally subsumed under Hindi in schools. This study had important implications for determining the role of mother tongue in education for policymakers, government officials, educationists, and teachers as the findings indicate a need for change in language policy and procedures.50 50 $^{\text {th }}$ Report of the Commissioner for Linguistic Minorities in India(2013) advised Government of West Bengal to implement the Three Language Formula upto class XII to enable the linguistic minority students to learn their languages as a subject at the Secondary stage of education and with a view to encouraging multilingualism and national integration. Newar and Singh (2017) studied the problems of Gorkha tribes in India. Gorkhas had been facing with a unique identity crisis with regard to their Indian citizenship, minority status,and constitutional status. Those authors opined that strong demands for their rights led to the political unification of Gorkha people and subsequent separate statehood demand. 
The review of the related literature helped the researcher in arriving at the following phenomenon:

* Linguistic minorities often feel discriminated against by the current language policy.

* They experience on a daily basis that their mother tongues are deemed worthless dialects that have little utility in modern life.

* The prime reason behind linguistic conflicts is the fear of loss of linguistic identity by the linguistic minorities.

* The review of related literature gave the researcher an understanding of the crisis of the linguistic minorities and corresponding research gap in studying their problems.

\subsection{Analysis and Interpretation}

To understand acculturation perspective in secondary curriculum the researcher has selected The Textbooks, named Bliss and Sahitya Sanchayan for content analysis. Those are based on the new curriculum and syllabus, tried to remain in focus with the vision of NCF 2005. The pieces selected in the series are aimed to expose the learners to the thoughts and writings of the world's best writers and thinkers.

From thematic perspective the textbooks are equipped with different genre of writing. Tales of Bhola Grandpa is humorous in tone whereas All About Dog talks about societal norms. The learners can have a wildlife exposure through A Day in the Zoo where the writer narrates about the zoo. Tom Loses a Tooth, A Shipwrecked Sailor, Himalaya Darshana, Niruddes is primarily concerned with the theme of adventure and travel. The textbook include science fiction like All Summer in a Day and an essay on the need of science writing in Bengali language by Rajshekhar Basu. The poetry section primarily occupied with romantic poems where the most of the poem contain the theme of nature in poems like Autumn, Mild the Mist upon the Hill, Nongar etc. The theme of Indian freedom movement is reflected in the texts of PatherDabi, BhangarGaan, Proloyullas.

It is matter of great disappointment that thorough analysis of all the texts reveal that among all the writers and the poets who contributed in the curriculum of class IX and X, none represent from the background of linguistic minority. As a result, the students coming from linguistic minority group do not feel at par with the existing curriculum. Gradually, they develop a sense of identity crisis. None of the texts prescribed for Class IX and X represents the culture and customs of the linguistic minority group. As a result they gradually succumb and accommodate themselves with the dominant culture. However, the texts represent a varied spectrum of experiences and achievements. They will, certainly, help the students to build their vision and perspective to life. 


\section{LICNAEDULATIION \\ 27-29 March, 2020 \\ Oxford, United Kingdom}

\subsection{Major Findings}

* Almost all the writers and the poets who contributed in the curriculum of class IX and $\mathrm{X}$ Language text books as well as the theme they have delineated, raises the common consensus which is absolutely free from the culture of linguistic minorities and the result of which is that they may not feel linguistically and psychologically associated with the existing curriculum. In the observation of the researcher, this may lead to the dismal zone of identity crisis.

* Among all the text in Bengali curriculum of Class IX and X, none is written in the tribal dialect with which the linguistic minority students can associate themselves. Students belonging to the family of linguistic minorities and culturally estranged express themselves in relation to their own cultural and linguistic atmosphere. Students should learn about the standard dialect both in Bengali and English because they need to be associated with the mainstream by which they may feel the sense of oneness related to language and culture. But, text in their dialect should have found place in the present curriculum.

* The present curriculum has an international fervor along with text from national level and regional level. But text associated with culturally marginalized group is not found. International writing is undoubtedly a good exposure for the construction of students' global identity but every student should feel the exuberance of his own culture which is to be reflected in his own curriculum. This is required not only for linguistic and cultural perspective but also from the humanitarian perspective.

* The text exercises in English textbooks mainly focus on objective type of question and descriptive type of question is ignored. The teachers, actually engaged in the day-today teaching learning process may face the problem where development of students' spontaneous thinking skill and Meta cognitive skill acquire less space in the text exercises.

* The present study locates neither the thematic nor the contributors' representation of linguistic minorities in the prescribed texts. Curriculum must have an inclusive focus. This inclusiveness of curriculum is the watchwords of maintaining the majorityminority dichotomy. Irrespective of majority and minority the curriculum must focus on inclusiveness. 


\section{Conclusion}

Linguistic minorities are generally bi-/multilingual. The functional use of their mother tongue is generally restricted to the home and in-group interaction while the dominant language(s) of the environment perform the role of other functions, such as in education, administration and mass communication. Thus language, singly or in clusters, acts as a token of cultural identity of individuals and groups.

Pan Indian national cultures act as super ordinate language while regionalized cultures behave like localized distinct dialects. Regionalized cultures like dialects usually do not detract from the wider loyalties to a nation; rather it provides the people with a sense of belonging instead of inbreeding feeling of rootless life. It is the cultural pluralism within a multilingual framework with a sense of superordinate feeling of being one nation which is the Indian identity.

A new perspective of language planning needs to be emerged. This perspective should be based on the recognition of language as a societal resource and its proper development and utilization, the principles of language rights, equality and differential treatment, and the inherent as well as functional value of linguistic diversity. With a fuller characterization and development of this perspective not only the language planning theory will gain in depth and systematically, but it will also make a more positive contribution to the growth and sustenance of multilingualism and multiculturalism. Through the findings of this research, the researcher expects the concerned stakeholders to take up the issue related to cultural representation of the linguistic minorities in the secondary curriculum.

\section{Acknowledgment}

This paper is an output of the dissertation project for partial fulfilment of the award of Master of Philosophy (M.Phil.) in Education 


\section{ILNAEDULATION \\ 27-29 March, 2020 \\ Oxford, United Kingdom}

\section{References}

- Bakshi, P. (2013). Language Policy, Politics and Ideology in Mewat: Comparative Case Studies of Mewati in Two School Types. University of Sydney, Retrieved on 01.10 .15

http://ses.library.usyd.edu.au/bitstream/2123/10121/1/Kerswell_P_thesis.pdf

- Bandopadhyay, G. (2010). The Impact of Cultural Milieu in Developing Second Language awareness: Towards an Intercultural Shelter of Mind. (Sikshachintan, International Vol.4, pp. 41-49)

- Benedikter, T. (2009). Language Policy and Linguistic Minority in India. Berlin: LIT Verlag.

- Bourdieu, P. (1992). Language and Symbolic Power. (Polity Press).

- Gorter, D. (2012). Minority Languages in the Linguistic Landscape. Palgrave MacMillan.

- Hasnain, S.I. (2007) Urdu Linguistic minorities and Education. Language in India, Volume 7. ISSN 1930-2940. Bloomington, MN 55438, USA.

- Jacob, A. (1972). Linguistic Minorities in India : Problems and Safeguards. in Imam, M. (ed), Minorities and the Law, N.M.Tripathy, Bombay.

- Kumar K.K. \& Jain K.K. (2012). Language Conflicts in Social Arenas: Reflections for the Business World. Sage Journals , Retrieved on 12.09.2015 http://jas.sagepub.com/content/48/1/64.abstract.

- Mitchell, L. (2009). Language, Emotion and Politics in South India: The making of a Mother Tongue. Indiana University Press.

- NCLM (2013). 50 TH Report of the Commissioner for Linguistic Minorities in India. Commissioner for Linguistic Minorities,Ministry of Minority Affairs, Government of India.

- Newar, S. \& Singh J. (2017). Movement OfGorkhas For Constitutional Status In India. International Journal of Innovative Research and Advanced Studies, Volume 4 , Issue 2. ISSN:2394-4404.

- Simpson A. (2007). Language and National Identity in Asia. Oxford University Press, USA.

- Shridhar, K.K. (1996). Language in Education: Minorities and Multilingualism in India. International Review of Education, Kluwer Academic Publishers. Netherlands

- Vanishree, V.M. (2011). Provision for Linguistic Diversity and Linguistic Minorities in India. Retrieved on 24.09.15 from http://www.languageinindia.com/feb2011/vanishreemastersfinal.pdf

- WBBSE (2016). Bliss. Class IX-X. The West Bengal Board of Secondary Education,Kolkata.

- WBBSE (2016). Sahitya Sanchayan. Class IX-X. The West Bengal Board of Secondary Education, Kolkata. 